\title{
Re: cm070928r
}

\section{Preparation of Ferromagnetic Cobalt Substituted $\mathrm{TiO}_{2}$ (anatase) Thin Films By Electrochemical Deposition}

Hao Wang et al.

\section{Supporting Information}

Experimental Procedures

$\mathrm{Ti}_{1-\mathrm{x}} \mathrm{Co}_{\mathrm{x}} \mathrm{O}_{2-\delta}$ films were deposited on $\mathrm{Si}$ and rolled Ti substrates of $99.99 \%$ purity $(10 \times 10 \times 0.125 \mathrm{~mm}$ supplied by Advent Ltd., UK). Before deposition of the films, the substrates were polished using $3 \mu \mathrm{m}, 1$ $\mu \mathrm{m}$ and $0.25 \mu \mathrm{m}$ diamond-polishing media successively, degreased in an ultrasonic bath, and finally rinsed with de-ionized water. $\mathrm{TiCl}_{4}$ (VWR, 99\%) and hydrogen peroxide, $\mathrm{H}_{2} \mathrm{O}_{2}$ (27 wt.\% solution in water; Advent Ltd., UK) were used as starting materials for the deposition of the $\mathrm{TiO}_{2}$ films. A solvent was prepared by adding these two solutions to a methanol-water mix (3:1 volume ratio). The stock solution contained 0.005 $\mathrm{M} \mathrm{TiCl}_{4}$, and $\mathrm{H}_{2} \mathrm{O}_{2}$ with a $\mathrm{TiCl}_{4}: \mathrm{H}_{2} \mathrm{O}_{2}$ ratio of $1: 2$. To introduce Co to the films, $\mathrm{CoCl}_{2} \cdot 6 \mathrm{H}_{2} \mathrm{O}(97.5 \mathrm{wt} \%$ Hopkin and Williams ltd. UK) was added directly to the stock solution prior to deposition, with the atomic ratio of Co: Ti being 1:20. For the electrolytic deposition a three electrode cell was used with a mercury sulphate electrode (MSE) as a reference electrode, Pt wire was used as the counter electrode, with $\mathrm{Si}$ or $\mathrm{Ti}$ substrates being the working electrodes. The prepared solution was used as the electrolyte. Each film was deposited galvanostatically at a temperature of approximately $0^{\circ} \mathrm{C}$. A current density of $-20 \mathrm{~mA} \cdot \mathrm{cm}^{-2}$ was applied to the cell for 45 minutes. After electrodeposition, the as-deposited films were removed from the solution and washed gently with de-ionized water in order to remove any $\mathrm{Cl}^{-}$impurities.

High temperature x-ray diffraction (HTXRD) was used for in-situ studies of film crystallisation and phase change as a function of temperature. Subsequently each of the as-deposited films were thermally treated at $400{ }^{\circ} \mathrm{C}$ for one hour to crystallise the anatase phase; the heating rate was $10^{\circ} \mathrm{C} \cdot \mathrm{min}^{-1}$. Field emission gun scanning electron microscopy (JEOL, Model Gemini) equipped with energy dispersive x-ray spectroscopy (EDS); and atomic force microscopy (AFM, Molecular Imaging) was used to study the morphology of the obtained films. The crystal structure was determined by x-ray powder diffraction using a Philips PW 1710 diffractometer with $\mathrm{CuK}_{\alpha}$ radiation. Room temperature magnetization was measured as a function of applied field in an Oxford Instruments vibrating sample magnetometer (VSM), with the applied field parallel to the film surface, and parallel to the longer side of the substrate (approx $10 \mathrm{~mm} \times 6 \mathrm{~mm}$ ). A linear background term arising from the substrate and sample was subtracted from the raw data. In order to remove any influence of the metal substrates on electrical or magnetic measurements the films used for VSM tests were deposited on to Si substrates; the crystallography and morphology of films formed on both substrates were consistent, although better adhesion was observed for the Ti substrates. 